\title{
III
}

\section{A CASE OF KERATODERMA BLENNORRHAGICUM}

\author{
By J. G. MURDOCH, M.A., M.B., Ch.B.
}

The following, $A$ Case of Keratoderma Blennorrhagicum, seems to present some special points which, apart from the rarity of the condition, make it worthy of recording.

This extremely unusual skin condition and its association with gonorrhœa was first noted by Widal in 1893 . Sequeira recorded the first case in this country in I9Io, and described it as a " symmetrical horny eruption of the soles occurring in gonorrhœa." Since then about 80 cases have been recorded, and although the ætiology of the skin lesion has not yet been definitely proved, its peculiar appearance and invariable association with a previous severe gonorrhœa suggests that it is a definite, if rare, complication of that disease.

The typical lesion starts as a series of tiny vesicles which enlarge, rupture and form encrusted conical papules. These enlarge in turn and eventually coalesce, forming irregular horny patches which in the course of a few weeks peal off leaving a fairly normal and unindurated skin. The patches commonly appear first on the soles of the feet, always symmetrically. In some cases they have appeared also on the trunk and upper extremities.

The following case was admitted to the Birkenhead Municipal Hospital in December, I935. The patient, who was a ship's steward, aged forty-two, gave this history :-

In I9I3 he first contracted gonorrhœa, and was " cured." In I922 he had a recurrence of the discharge and again received treatment. In I928 he developed " sub-acute rheumatism," involving hips, knees, ankles and shoulders. This persisted for a year, was then diagnosed as gonorrhœal arthritis and was cured in three months. In September, I935, he had either a recurrence of the discharge or suffered a fresh infection and was 


\section{CASE OF KERATODERMA BLENNORRHAGICUM}

treated on board ship. At the beginning of November his right ankle started to swell and he developed pain in the hip and shoulder joints. During November (he stated) blisters appeared on the soles of both feet, which burst, leaving small raw areas which became covered with horny skin while fresh blisters appeared.

He was admitted to the hospital on December 9th.

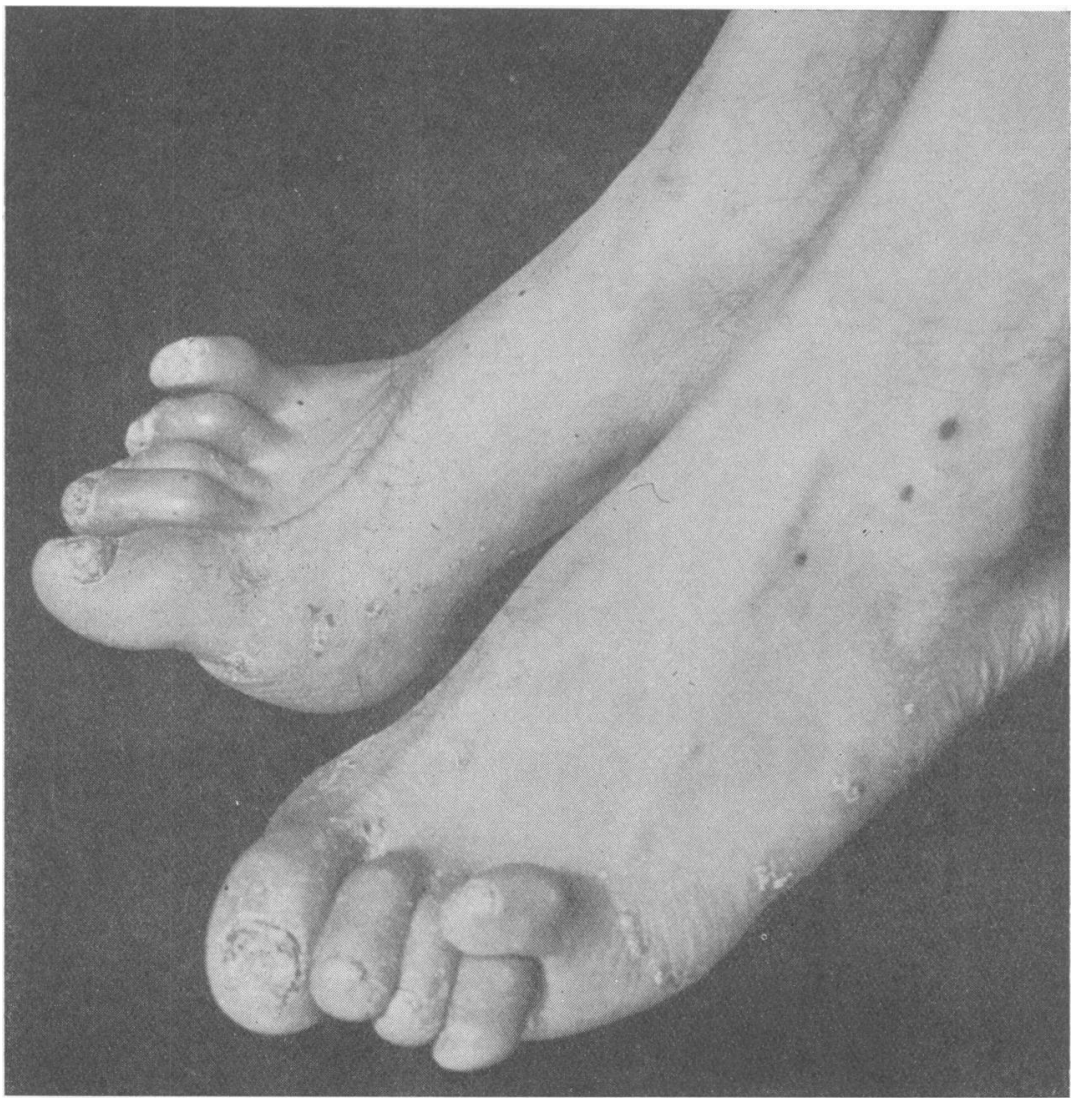

FIG. I.

The arthritis was still causing considerable pain. The soles of both feet showed a marked hyperkeratosis and the "geographical map-like areas" of the typical keratoderma blennorrhagicum. It was noted that the toe nails and the tissue of the nail beds were also markedly thickened.

Between the last week of December and the middle of 


\section{BRITISH JOURNAL OF VENEREAL DISEASES}

January entire layers of skin were pealed off the soles, and all the toe nails separated in turn. The condition of the soles became normal, but the thickening and piling up of the nails recurred.

In the beginning of February the finger nails of each hand began to show a similar thickening and to be forced up in the same way by a proliferation of the tissue of the

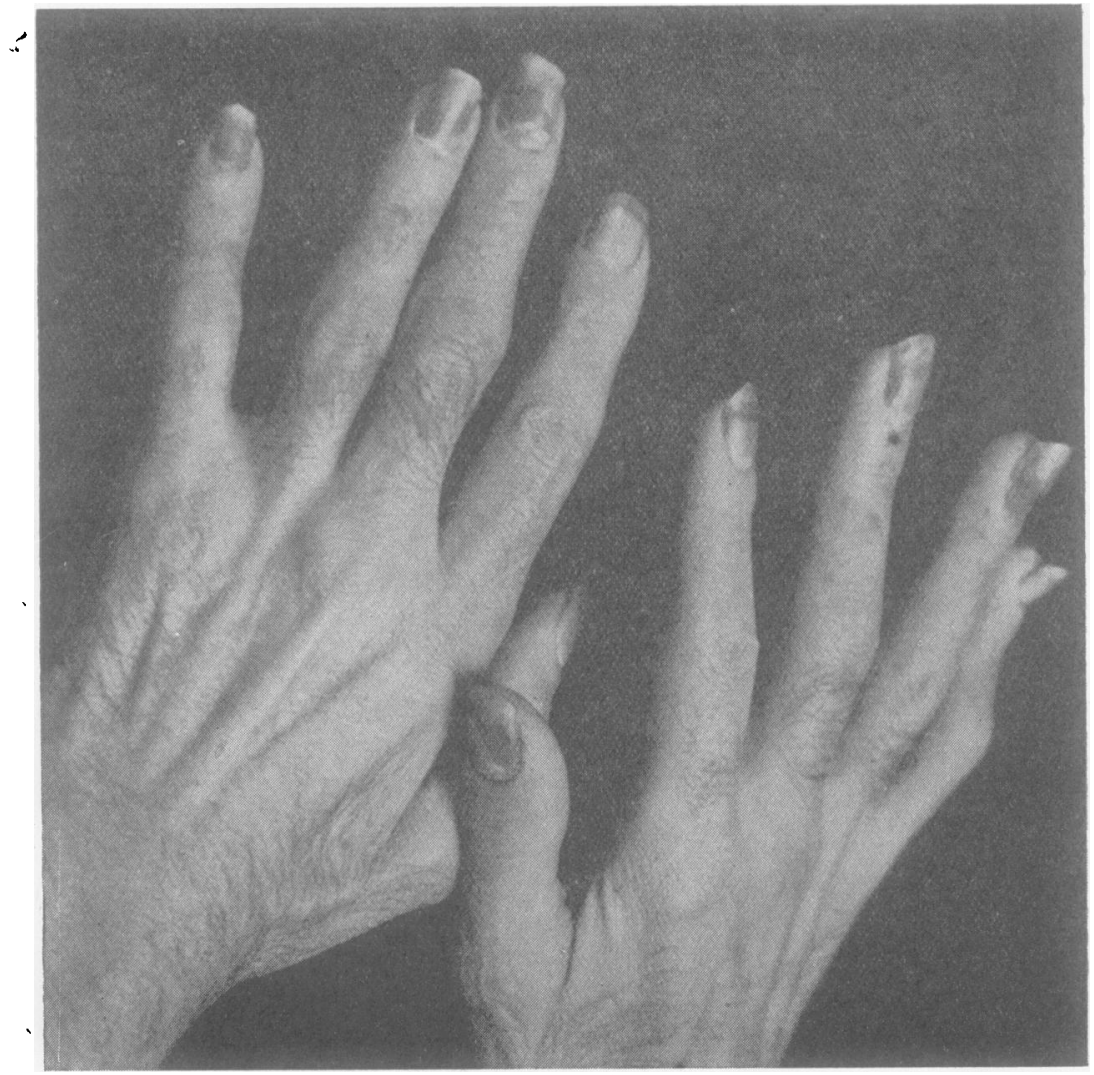

FIG. 2.

nail bed. The palms were not affected, but many small red nodules appeared on the dorsal surface of the skin of the fingers proximal to the nails. These nodules became covered with horny scales which eventually dropped off, leaving normal skin behind. Several similar nodules appeared on the forehead, in front of the ear, and on the back between the shoulder-blades, all of which disappeared in the same manner. 


\section{CASE OF KERATODERMA BLENNORRHAGICUM}

The patient had a very cachectic look throughout, and during March developed a catarrhal jaundice, probably of a toxic nature, which cleared up in a few weeks. The Wassermann reaction was negative.

The most interesting feature of the case, apart from the rarity of the condition itself, would seem to be this special thickening of the nails and the tissues underneath, followed by the actual shedding of all the nails. The accompanying photographs show the peculiar manner in which the nails were affected. The toe nails had already been shed before the photographs were taken; those of the fingers had not yet separated.

I am indebted to Dr. R. A. Grant, Medical Superintendent, for permission to publish these notes. 